\title{
Search for evidence of trend slow-down in the long-term TOMS/SBUV total ozone data record: the importance of instrument drift uncertainty
}

\author{
R. S. Stolarski ${ }^{1}$ and S. M. Frith $^{2}$ \\ ${ }^{1}$ NASA Goddard Space Flight Center, Greenbelt, MD 20771, USA \\ ${ }^{2}$ Science Systems and Applications, Inc., Lanham, MD 20706, USA
}

Received: 23 January 2006 - Published in Atmos. Chem. Phys. Discuss.: 16 May 2006

Revised: 30 August 2006 - Accepted: 31 August 2006 - Published: 8 September 2006

\begin{abstract}
We have developed a merged ozone data set (MOD) for the period October 1978 through June 2006 combining total ozone measurements (Version 8 retrieval) from the TOMS (Nimbus 7, Earth Probe) and SBUV/SBUV2 (Nimbus 7, NOAA 9/11/16) series of satellite instruments. We use the MOD data set to search for evidence of ozone recovery in response to the observed leveling off of chlorine and bromine compounds in the stratosphere. A crucial step in any time series analysis is the evaluation of uncertainties. In addition to the standard statistical time series uncertainties, we evaluate the possible instrument drift uncertainty for the MOD data set. We combine these two sources of uncertainty and apply them to a cumulative sum of residuals (CUSUM) analysis for trend slow-down. For the extra-polar mean between $60^{\circ} \mathrm{S}$ and $60^{\circ} \mathrm{N}$, the apparent slow-down in trend is found to be clearly significant if instrument uncertainties are ignored. When instrument uncertainties are added, the slowdown becomes marginally significant at the $2 \sigma$ level. For the mid-latitudes of the northern hemisphere $\left(30^{\circ}\right.$ to $\left.60^{\circ} \mathrm{N}\right)$ the trend slow-down is highly significant at the $2 \sigma$ level, while in the southern hemisphere the trend slow-down has yet to meet the $2 \sigma$ significance criterion. The rate of change of chlorine/bromine compounds is similar in both hemispheres, and we expect the ozone response to be similar in both hemispheres as well. The asymmetry in the trend slow-down between hemispheres likely reflects the influence of dynamical variability, and thus a clearly statistically significant response of total ozone to the leveling off of chlorine and bromine in the stratosphere is not yet indicated.
\end{abstract}

Correspondence to: R. S. Stolarski

(stolar@polska.gsfc.nasa.gov)

\section{Introduction}

The release of a host of ozone-depleting substances by human activity led to a decrease in the total ozone abundance that has been well documented by satellite and ground-based measurement systems (e.g. WMO, 1999, 2003). The pattern of decline is consistent with theoretical predictions of the impact of chlorine and bromine compounds from chlorofluorocarbons (CFCs), halons, and methyl bromide on ozone (e.g. Stolarski et al., 1992; Staehelin et al., 2001; WMO, 2003). In response to the observed ozone loss, countries around the world adopted the Montreal Protocol and subsequent amendments calling for limitations on production and use of ozone-depleting substances. In the last five years, reductions of chlorine and bromine compounds have been observed. Measurements show that the surface levels of compounds containing chlorine and bromine have peaked and begun to decrease slowly (Montzka et al., 1999, 2003; WMO, 2003). The concentration of hydrogen chloride $(\mathrm{HCl})$ in the upper stratosphere - an indicator of CFCs - has also peaked and begun its slow decline (Anderson et al., 2000; Rinsland et al., 2003).

Many advances have been made in the study of stratospheric ozone and ozone depletion since the inception of the Montreal Protocol, but the most basic questions remain:

1. When will a slow-down in the negative ozone trend be detected?

2. When will a statistically significant upward trend in ozone be detected?

3. Will the ozone return to levels similar to those before depletion began?

Long-term, well-calibrated data sets are required to address these questions. The Total Ozone Mapping Spectrometer (TOMS) and Solar Backscatter Ultraviolet (SBUV and SBUV2) series of instruments use the backscatter ultraviolet

Published by Copernicus GmbH on behalf of the European Geosciences Union. 
Instrument Data used to create Merged Ozone Dataset

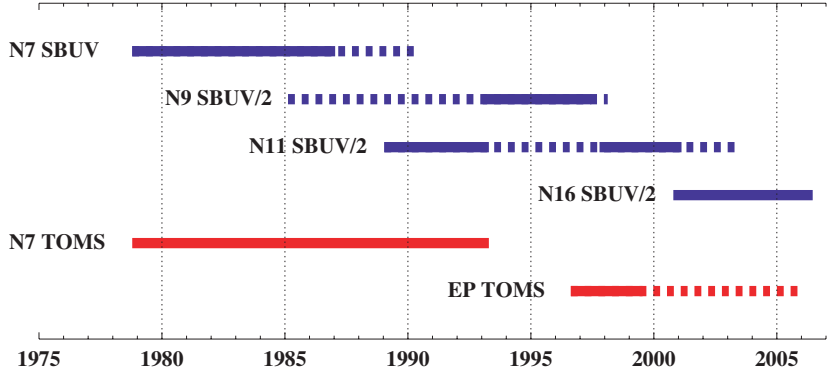

Fig. 1. Instruments used to create merged ozone data set. Solid lines indicate time when data was used. Dashed lines indicate time when data was available, but not used for reasons explained in the text.

technique to infer total column ozone abundance. These instruments have provided nearly continuous data at high spatial resolution since the launch of the Nimbus 7 satellite in 1978. Long-term calibration of each instrument data set is maintained using a series of hard and soft calibration techniques (Taylor et al., 2003; Deland et al., 2004). We have combined data from the individual instruments to construct a single merged ozone data set (MOD). We use instrument inter-comparisons to estimate and account for calibration differences among the instruments and then average the data during instrument overlap periods. In this study, we use the MOD data set to address the first of the questions above, namely, can we detect a slow-down in the negative ozone trend in the data.

Despite the best efforts to calibrate each instrument data set, measurement noise and potential residual calibration drift remain. In addition, characteristic biases between TOMS and SBUV-type measurements are present. These uncertainties carry over into the MOD data set, and must be properly characterized. We use a Monte-Carlo approach to obtain an overall estimate of uncertainty in the MOD data set, including terms for systematic and random differences between instruments, and potential instrument drift. These uncertainties, when combined with statistical uncertainty, impact the significance of the long-term trend estimates, as well as the estimates of subsequent changes in the trend.

\section{The instrument record and the MOD data set}

The current MOD total ozone data set includes measurements from 6 satellites: Nimbus 7 TOMS, Nimbus 7 SBUV, NOAA 9, 11, and 16 SBUV/2s, and Earth Probe (EP) TOMS (Heath et al., 1975; Frederick et al., 1986; Hilsenrath et al., 1995; McPeters et al., 1996; McPeters et al., 1998). We use the data released by the individual instrument teams, and then apply additional adjustments to each record such that the merged data set is calibrated relative to a reference standard. We use the EP TOMS data from 1996 through mid-

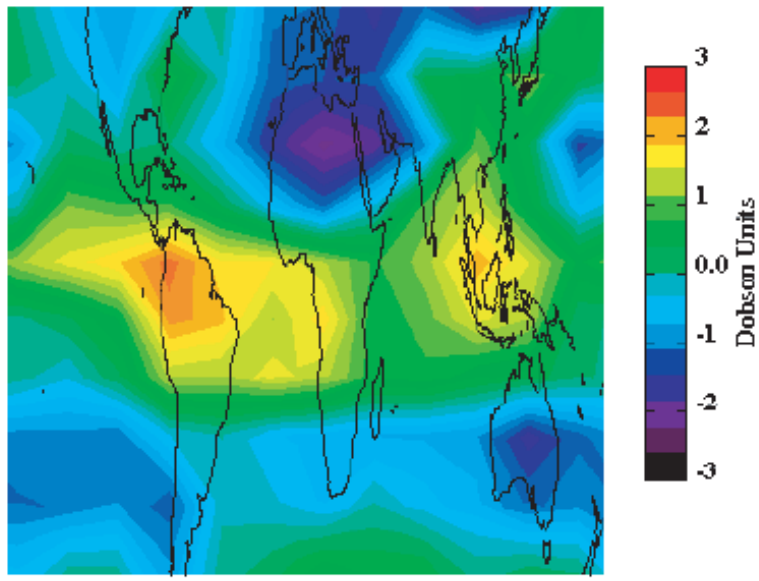

Fig. 2. Difference between Nimbus 7 TOMS and Nimbus 7 SBUV measurements for total ozone averaged over 8 years of concurrent operation.

1999 as the calibration standard, but note that the absolute calibration of the time series is not critical for trend analysis studies. The temporal coverage of the individual data sets are shown in Fig. 1.

We use the periods denoted by the solid lines to construct the MOD data set. The dashed lines in Fig. 1 represent periods when, though measurements are made, there are calibration, stability or viewing angle (satellite orbit near terminator) issues associated with a given instrument. We compare data in periods of instrument overlap, and use the mean of the differences averaged from $50^{\circ} \mathrm{S}-50^{\circ} \mathrm{N}$ over the available overlap period to determine the adjustment needed to match the standard calibration.

The difference in ozone between two satellites typically shows a characteristic spatial distribution, in addition to a simple offset. Figure 2 shows the difference between Nimbus 7 TOMS and Nimbus 7 SBUV grid averages over their $8+$ year overlap period. Individual instrument gridded-mean maps are created first, and then differenced. Some of the differences are due to better quality aerosol corrections by the TOMS scanning instrument, as compared to the nadir-only SBUV. Other instrument differences, such as the field of view and orbit precession, can also affect the ozone retrieval and potentially lead to systematic differences between the instruments. The interactions within the algorithm are complex, and many of the resulting variations between satellite measurements are not understood. To best characterize the overall difference between the data sets, we use the mean of the differences at all longitudes and latitudes between $50^{\circ} \mathrm{S}$ and $50^{\circ} \mathrm{N}$. We chose this approach over a latitude-dependent adjustment or an adjustment based on comparisons in a particular region because the differences are not zonal in nature, and we do not understand the distribution well enough to determine which area gives the "correct" bias. 
Our first MOD data set was put together in 2000. Fioletov et al. (2002) compared this data to several other satellite and ground-based total ozone data sets and found agreement within $2 \%$. There have since been several modifications, the latest being to include the Version 8 data from TOMS and SBUV (Bhartia et al., 2004). Figure 3 shows the mean comparisons of total ozone as a function of month between different satellites from the Version 7 data and Version 8 data. To compute these differences, $5^{\circ}$ zonal mean monthly time series are constructed for each satellite using all available data. Then in satellite overlap periods, the zonal mean time series are compared (i.e., space-time match-ups are not required). For each month, the differences in the $5^{\circ}$ zonal means are area weighted and averaged between the latitudes of $50^{\circ} \mathrm{S}$ and $50^{\circ} \mathrm{N}$. The external adjustments applied to each record are the average of these differences, as denoted by the thin solid lines. In Version 7, a special time-dependent adjustment was made for Nimbus 7 TOMS, to account for an error that was later corrected in Version 8.

Note that the V7-based MOD data set included data from the NOAA 14 SBUV/2 instrument, and from the NOAA 9 instrument during its overlap period with Nimbus 7 TOMS. These data were deemed by the instrument teams to be of inferior quality, and are not included in the V8-based data set. The current MOD data set also includes NOAA 16 data through June 2006. The NOAA 16 data from the beginning of the record have been reprocessed using the best calibration information available through August 2005. The reprocessed NOAA 16 data are provisional at this time, but little change is anticipated when a final processing becomes available (Matt Deland, personal communication).

The mean differences among the instruments are significantly reduced in the Version 8 data set. This is because the Version 8 algorithm includes a reanalysis of the calibration to put all of the SBUV satellite instruments on a common reference standard (relative to SSBUV shuttle flight data), reducing the need for additional adjustments (Deland et al., 2004). Although mean adjustments, such as those applied to the V7-based MOD data set, inter-calibrate the data on average, variations due to an instrument calibration error can have a latitude and seasonal dependence (Bhartia et al., 1996). In Version 8 , the calibration corrections are made to radiance measurements and then propagated through the algorithm, giving a more realistic ozone correction.

As seen in Fig. 1, both the NOAA 9 and NOAA 11 SBUV/2 have some length of overlap with both TOMS instruments, so either can be used to set the calibration of Nimbus 7 TOMS to the EP TOMS standard. We use the NOAA $11 \mathrm{SBUV} / 2$ data to bridge the gap, because NOAA 11 has a longer overlap with both Nimbus 7 and EP TOMS, and analysis by the instrument team indicates that the NOAA 11 calibration is maintained over the terminator period (Matt Deland, personal communication). Therefore we treat the NOAA 11 data before and after the terminator as a single consistent record. We also note that there is no overlap be-

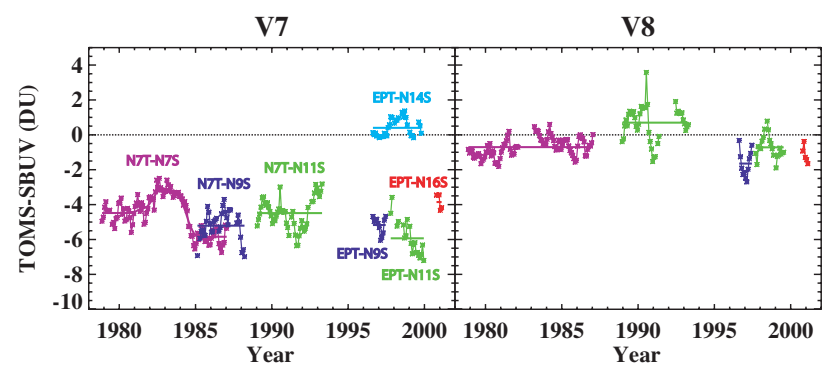

Fig. 3. TOMS-SBUV comparisons for all available overlap periods plotted vs. time (3-month overlap between Nimbus 7 TOMS and NOAA 9 SBUV in early 1993 not shown). Version 7 data are in the left panel and Version 8 data are in the right panel. Plotted differences are averaged from $50^{\circ} \mathrm{N}-50^{\circ} \mathrm{S}$. EP TOMS-NOAA 16 differences are computed using NOAA 11 SBUV/2 as a transfer standard. We use these differences to determine calibration offsets to apply to each data set before creating the MOD data set.

tween the EP TOMS data used in this analysis and the NOAA $16 \mathrm{SBUV} / 2$ data. In this case, we use the NOAA 11 data, which overlaps both, as a transfer standard to estimate the difference between the EP TOMS and NOAA 16 data. The calibration information is then propagated through the data sets by first calculating the offset between the EP TOMS data and the NOAA 9, NOAA 11, and NOAA $16 \mathrm{SBUV} / 2$ data, then using the adjusted NOAA $11 \mathrm{SBUV} / 2$ data to establish the calibration of the Nimbus 7 TOMS, and then the Nimbus 7 SBUV data. Finally, all of the adjusted data sets are averaged during periods of overlap, creating a single consistent data set.

\section{Evaluating instrument uncertainties}

When combining multiple satellite records into a long-term data set, we have two sources of error: the long-term drift in each data record, and the spatial pattern of differences between the data sets, which limits our ability to perfectly determine the offset of one record relative to the other. As seen previously in Fig. 2, differences between satellite measurements often have a characteristic pattern. These differences represent the systematic bias between the two instruments. The standard deviation of the 8-year mean difference pattern between the Nimbus 7 TOMS and SBUV instruments (Fig. 2) is $1 \mathrm{DU}$.

Figure 4 shows the mean differences between Nimbus 7 TOMS and Nimbus 7 SBUV for two individual years, 1979 and 1986. The difference pattern is similar between the two years (and other years not shown), but there is clearly a yearto-year variability about the mean bias. The variability about the bias is also illustrated in Fig. 3 for each pair of TOMSSBUV instrument overlaps. This variability and the length of the overlap period give a statistical measure of how precisely we can determine the systematic bias between two 


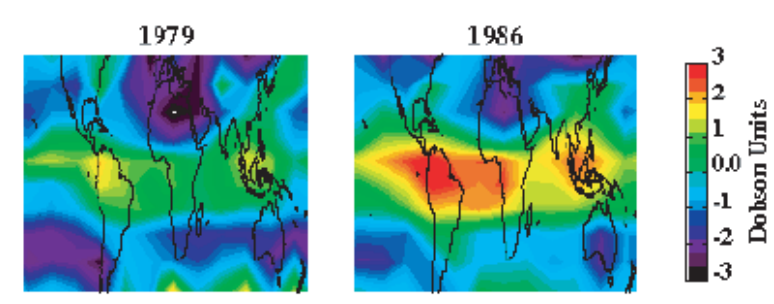

Fig. 4. Difference between Nimbus 7 TOMS and Nimbus 7 SBUV measurements of total ozone averaged over 1979 in left panel and 1986 in right panel.

instruments. A longer overlap period and/or reduced variability lead to more confidence in the calculated bias, and a reduced offset uncertainty. Therefore the offset uncertainty at any given location is based on the spatial variability of the systematic bias, and our ability to precisely estimate that spatial pattern (the time-dependent variability).

The year-to-year variability about the mean bias is correlated in time, which also affects the uncertainty in the bias estimate. As an example, consider the Version 8 Nimbus 7 TOMS - Nimbus 7 SBUV monthly difference time series in Fig. 3 (purple curve in right panel). The standard deviation of this difference time series is $0.45 \mathrm{DU}$. If the data were uncorrelated, the standard error of the mean would decrease rapidly as the square root of the number of months of overlap as shown by the dashed line in Fig. 5. The actual decrease in the uncertainty with additional months of overlap proceeds more slowly because of the auto-correlation of the data, as shown by the solid line in Fig. 5. We fit the overlap difference time series with an auto-regressive lag-1 (AR(1)) model to derive an estimate of how the uncertainty decreases with increasing overlap. This AR(1) model was then used to generate a large number (1000) of time series with a given length. The probability distribution of means for these series was Gaussian and its standard deviation gave the estimate for the non-systematic part of the overlap uncertainty (upper curve in Fig. 5).

The result is an uncertainty of about $0.35 \mathrm{DU}$ for a 5 month overlap, decreasing to about $0.15 \mathrm{DU}$ for a 5 -year overlap. For each overlap between satellites, the uncertainty in establishing their relative calibration was estimated as the root sum of squares of two numbers: the statistical uncertainty from Fig. 5 for the number of months of overlap, and the 1.0 DU systematic uncertainty (1.75 DU for the overlap between NOAA 11 and NOAA 16).

Having estimated the uncertainty in establishing the possible calibration offset of two overlapping instruments, we now consider the possible drift of a single instrument during its lifetime. We will then combine estimates of the uncertainty in establishing instrument offset and of instrument drift uncertainty to obtain an estimate of overall instrument system drift uncertainty. The instrument drift uncertainty is

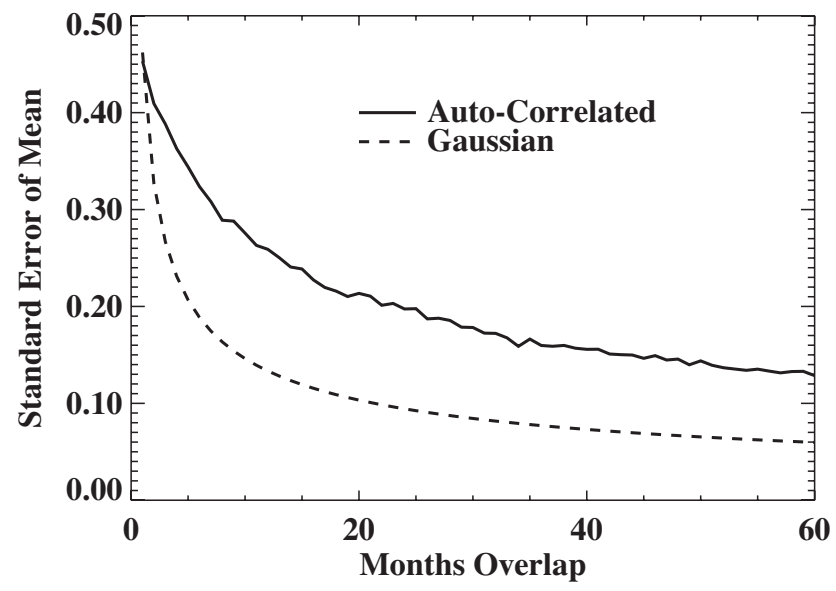

Fig. 5. Statistical uncertainty in establishing systematic bias between Nimbus 7 TOMS and Nimbus 7 SBUV as a function of the number of months overlap. Solid line is uncertainty with autocorrelation taken into account. Dashed line is standard error of the mean if data were uncorrelated.

difficult to assess. Herman et al. (1991) did a thorough evaluation of drift uncertainty for the Nimbus 7 TOMS during its first decade of measurements. The authors estimated the drift uncertainty in each component of the calibration for the Nimbus 7 TOMS instrument and propagated these through the entire algorithm process. They estimated a $2 \sigma$ uncertainty of $1.3 \% /$ decade or $\sim 4 \mathrm{DU} /$ decade. In this study, we assume that the Nimbus 7 TOMS drift uncertainty estimate applies to each of the other instruments. Labow et al. (2004) showed the EP TOMS data through 1999 have a small offset, but no long-term drift relative to a set of ground station data. Bhartia et al. (2004) estimate a theoretical precision of $1 \% /$ decade for the Version 8 SBUV algorithm and initial V8 SBUV calibration studies and comparisons with independent data indicate a long-term uncertainty of less than $3 \% / d e c a d e$ in the profile data (Deland et al., 2004; Ahn et al., 2004). Therefore a $1.3 \%$ /decade uncertainty for total ozone should be a reasonable estimate for all TOMS and SBUV instruments.

We combine the drift and offset uncertainties by constructing 1000 Monte-Carlo realizations for the sequence of instruments shown in Fig. 1. The range of individual realizations is plotted in Fig. 6. The thick green line denotes the standard deviation of the realizations calculated from the distribution at each time step. The blue line indicates two standard deviations.

The $2 \sigma$ instrument uncertainty in the year 2005 relative to the beginning of the record in 1979 is about 8 DU (Fig. 6). For the global average ozone amount of about $300 \mathrm{DU}$, this is $2.7 \%$ over 26 years or just slightly more than $1 \% /$ decade ( $\sim 3$ DU/decade). We note that the estimated drift uncertainty is less than that assumed for each individual instrument. Each time a new instrument is added to the time series, 


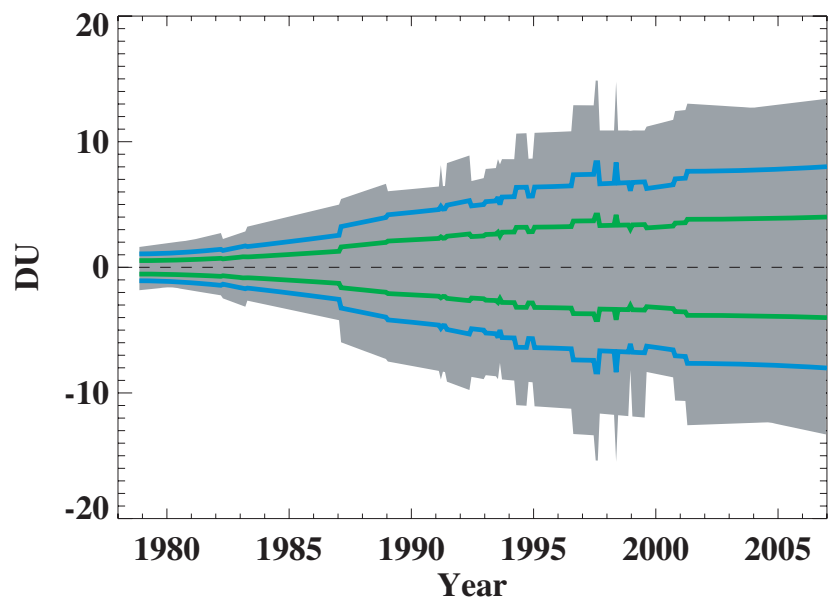

Fig. 6. Instrument drift uncertainty vs. time for the MOD data set. Green line indicates $1 \sigma$ uncertainty and blue line indicates $2 \sigma$ uncertainty.

the drift from the previous instrument ends, and a new drift begins. Thus the long-term drift is "reset" and the new drift may be in the opposite direction and partially compensate for the drift in the previous instrument. While these short-term drifts will manifest as correlated noise in the regression analysis, they are not as likely to alias into the long-term trend signal.

\section{Trend slow-down detection}

\subsection{CUSUM method}

We apply the MOD data set, with uncertainties, to the question of detecting the beginning of the column ozone recovery process. We use the cumulative sum of residuals (CUSUM), in which the cumulative sum of the differences in time between the data and an assumed statistical time-series model is used to characterize the data relative to the model. Reinsel (2002) first used this approach to evaluate changes in ozone trend. He described the method as a "useful graphical device to depict a relatively small change in pattern over time." Newchurch et al. (2003) expanded on the qualitative approach of Reinsel (2002), using the CUSUM method to quantify and assign significance to an apparent slow-down in the upper stratospheric ozone trend derived from SAGE measurements. They reported a statistically significant reduction in the ozone loss rate globally at $35-45 \mathrm{~km}$ altitude. They caution however that evidence of recovery at these altitudes cannot alone be interpreted as a recovery of the entire ozone column (Newchurch et al., 2003; WMO, 1999). More recently, Yang et al. (2006) performed a similar analysis using lower stratospheric and total column ozone from a variety of sources, including the MOD data set. The authors reported a highly significant slowing of ozone loss from all

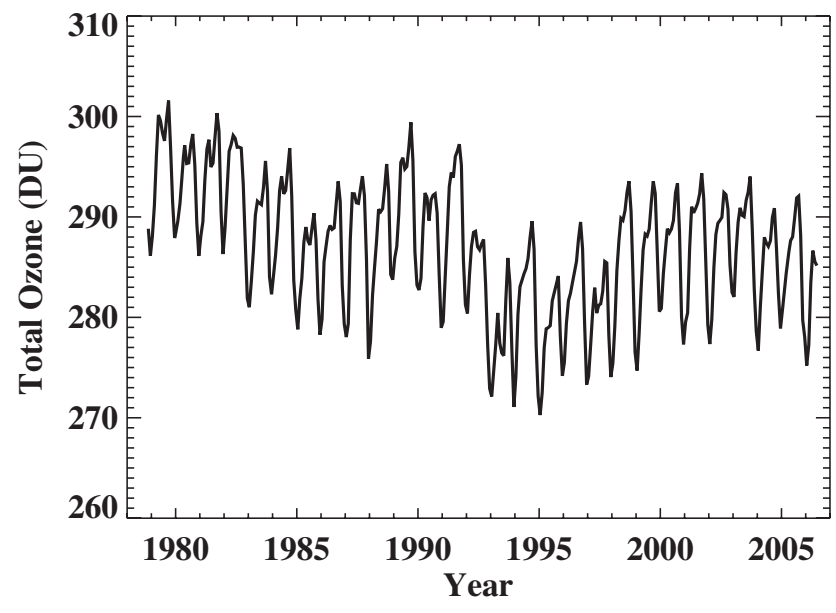

Fig. 7. Extra-polar $\left(60^{\circ} \mathrm{S}-60^{\circ} \mathrm{N}\right)$ time series of total ozone from MOD.

sources, including the $60^{\circ} \mathrm{S}-60^{\circ} \mathrm{N}$ MOD total ozone time series. Further analysis of the trend slow-down with altitude revealed a likely response to lessening chlorine/bromine levels from $18-25 \mathrm{~km}$, but changes from the troposphere to $18 \mathrm{~km}$ were responding more to dynamical/transport variations. In this study we follow the general approach of Newchurch et al. (2003) and Yang et al. (2006), but we use a different method for assigning statistical significance to the CUSUM results and we include the instrument uncertainty in the analysis, as detailed below.

We first apply the technique to the extra-polar average $\left(60^{\circ} \mathrm{S}-60^{\circ} \mathrm{N}\right)$ MOD time series, shown in Fig. 7. The data generally appear to be increasing since the minimum reached a few years after the Pinatubo volcanic eruption. These data demonstrate the difficulty in separating a possible change in the chemically-induced trend from other natural variations, such as the increase of ozone after Pinatubo and the upward phase of the solar cycle. We use our standard statistical time series regression model (Stolarski et al., 2006) to fit the data from 1979 through the end of 1996. We include terms for seasonal cycle, chlorine/bromine, QBO, and solar activity. Here we are fitting the time series only through the end of 1996, so we have replaced the chlorine/bromine term in Stolarski et al. (2006) with a linear trend. We also add terms to fit the volcanic impacts of Mt. Pinatubo and El Chichon. The volcanic proxies are from the GSFC two-dimensional chemistry and transport mode (2DCTM) simulations of the ozone response to volcanic aerosols (Stolarski et al., 2006). We then extrapolate the statistical time series parameters through the end of the MOD record. The residuals from the fit and its extrapolation are shown in Fig. 8 with the linear trend term added back into the time series for clarity. The red line indicates the linear trend term. The dashed line shows the residuals after 1996, the period over which the model fit is extrapolated. 


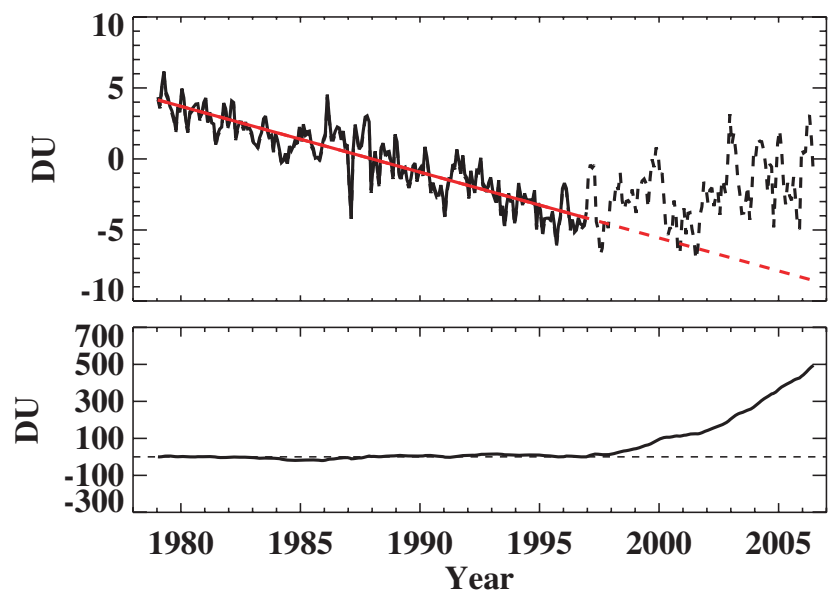

Fig. 8. Top: residuals from time series fit to extra-polar MOD time series with annually-averaged linear trend added back in. Dashed line is the extension of the residuals beyond the fitting time period of 1979-1996. Red line is the linear fit term. Bottom: cumulative sum of residuals from top panel as a function of time.

The cumulative sum of residuals is then calculated as the running total of the difference between the data anomalies of Fig. 8 and the red line. The bottom panel of Fig. 8 shows the accumulated residuals that rapidly become positive as most of the data is above the extended trend line. Graphically, these results suggest convincing evidence of a trend slowdown, but to assign significance, we must also account for the uncertainty of our assumed model. An error in the extrapolated trend due to autocorrelation (statistical error) or drift in the data (instrument error) would cause an error in the CUSUM that increases with time.

\subsection{CUSUM statistical uncertainty}

To evaluate the significance of the CUSUM we first determine the statistical uncertainty in the trend extrapolation. This uncertainty results from variability not explained by the statistical fit potentially aliasing into the trend term. The residuals are well described by an auto-regressive time series with lag of one month $(\mathrm{AR}(1))$. The lag one autocorrelation coefficient for the extra-polar time series residuals is 0.53 and the residual white noise is $0.96 \mathrm{DU}$. The Reinsel (2002) and Yang et al. (2006) studies included an AR(1) autocorrelation term in the assumed model, and computed the CUSUM from the white-noise residual. A trend derived from autocorrelated data has a greater uncertainty. Yang et al. (2006) scaled the white noise variance by factors designed to account for the greater uncertainty in the model mean value and trend, effectively increasing the value of CUSUM required for statistical significance. In this study, we use a Monte-Carlo approach to determine the requirement for significance. We create 1000 random realizations of the residual time series with the same auto-correlation and noise. We then fit a linear trend

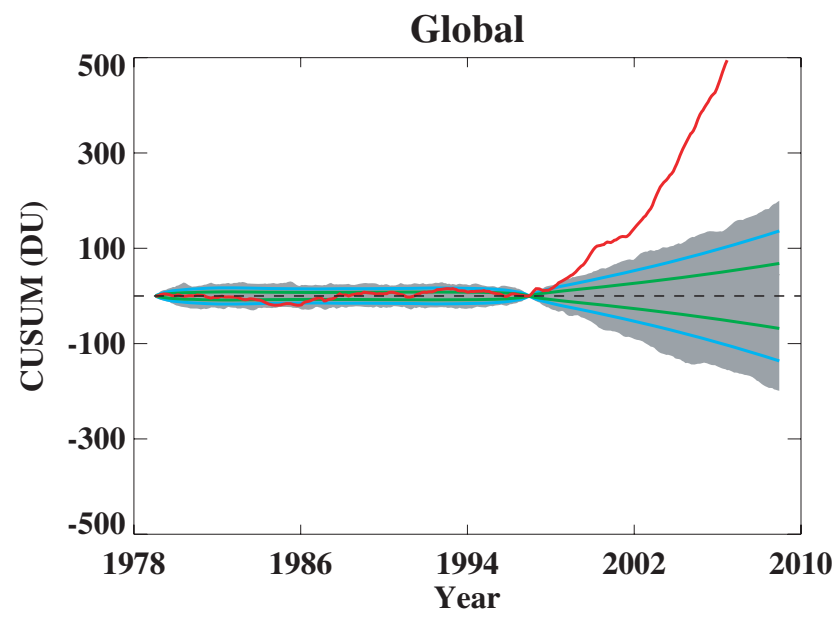

Fig. 9. Cumulative sum results without inclusion of instrument uncertainty. The gray region is formed by line plots of 1000 MonteCarlo cases used to determine uncertainty. The green thick line is the $1 \sigma$ width of the probability distribution of the 1000 cases as a function of time. The light blue line is the $2 \sigma$ width of the distribution. The red line is the cumulative sum of residuals for the data.

Table 1. Data uncertainties in DU/decade.

\begin{tabular}{llll}
\hline Region & Statistical & Instrumental & Total \\
\hline Global $\left(60^{\circ} \mathrm{S}-60^{\circ} \mathrm{N}\right)$ & 0.9 & 3.0 & 3.1 \\
N Midlat $\left(30^{\circ} \mathrm{N}-60^{\circ} \mathrm{N}\right)$ & 3.7 & 3.0 & 4.8 \\
S Midlat $\left(60^{\circ} \mathrm{S}-30^{\circ} \mathrm{S}\right)$ & 3.8 & 3.0 & 4.9 \\
Tropical $\left(30^{\circ} \mathrm{S}-30^{\circ} \mathrm{N}\right)$ & 1.4 & 3.0 & 3.3 \\
\hline
\end{tabular}

through the end of 1996, and extrapolate that trend as our assumed model. The time series realizations have no explicit trend, but may have a non-zero trend through 1996 because of the correlated nature of the noise. The range of resulting CUSUMS is denoted by the gray shading in Fig. 9. By including the autocorrelation in the realizations, we can directly estimate potential errors from statistical model uncertainties in the range of resulting CUSUMS. At each time, the distribution is Gaussian with the $1 \sigma$ and $2 \sigma$ variability indicated by the green and blue lines respectively. The CUSUM for the data is shown in Fig. 9 as the red line. Figure 9 shows a significant trend slow-down in the extra-polar time series when only statistical (including autocorrelation) uncertainties are considered. The CUSUM calculation agrees with that in figure 2 of Yang et al. (2006) and the $2 \sigma$ error criteria in 2004 derived using the Monte-Carlo approach is slightly lower than that calculated using the theoretical approach.

\subsection{CUSUM instrument uncertainty}

The next step is to include the instrument drift uncertainty for the time series. We again create 1000 artificial time series, 
each with its own realization of the instrument offset and drift plus the statistical uncertainty. Table 1 shows the estimated statistical and instrument uncertainties for four regions of the globe along with the combined uncertainties determined by a root mean sum of squares. The statistical uncertainty is a combination of the residual white noise and the AR(1) autocorrelation, as estimated from the time series. The instrument error for each time series is $1 \% /$ decade or $3 \mathrm{DU} /$ decade, as derived in Fig. 6. Figure 10 shows the range of CUSUMs for the 1000 artificial time series plotted in gray. Again the green and blue lines indicate the $1 \sigma$ and $2 \sigma$ variability in the distributions. When instrument uncertainty is added to the extrapolar data, the overall uncertainty of the resulting CUSUM is significantly increased. The CUSUM of the data shown in red is now only marginally significant at the $2 \sigma$ level. Interestingly, the CUSUM for this case reaches the $2 \sigma$ level within a few years and then stays near this level throughout the rest of the record. The chlorine/bromine record is changing slowly in time, so short term excursions such as this in the CUSUM are likely due to dynamical fluctuations, which are not represented in the statistical model. When ozone changes due to the chlorine/bromine signal dominate the CUSUM, the $2 \sigma$ line will be crossed and a clear separation will ensue. This is discussed more fully below with respect to the contrast between the northern and southern mid-latitudes.

The overall uncertainty values in Table 1 demonstrate the influence of the instrument uncertainty in time series with varying statistical characteristics. The relative impact of instrument uncertainty is less for time series with greater statistical variability, such as zonal average data over smaller latitude ranges. For a time series at a particular location, the instrument drift uncertainty is much smaller than the statistical uncertainty. For the extra-polar region $\left(60^{\circ} \mathrm{S}-60^{\circ} \mathrm{N}\right)$, the total uncertainty is dominated by instrument drift uncertainty, while at mid-latitude regions $\left(30^{\circ} \mathrm{N}-60^{\circ} \mathrm{N}\right.$ and $60^{\circ} \mathrm{S}-$ $30^{\circ} \mathrm{S}$ ), the statistical and instrument uncertainties are comparable. Figure 11 shows the CUSUM plots for the northern and southern mid-latitudes. The analysis indicates a significant slow-down in the trend at northern mid-latitudes, and suggests a slow-down in the southern mid-latitudes, but at only the $1.6 \sigma$ significance level. The derived significance level is based in part on the size of the instrument uncertainty, which was computed using several assumptions. We therefore tested the sensitivity of our results to a possible overestimate of the instrument uncertainty. The CUSUM is most sensitive to the inclusion of instrument uncertainty for the extra-polar time series. This can be seen in Figs. 9 and 10. In Fig. 9, the instrument uncertainty is set to zero. The $\mathrm{NH}$ CUSUM results are always significant, and the SH CUSUM curve nearly reaches the $2 \sigma$ level when the instrument uncertainty is set to zero (not shown). Given these boundaries, our primary conclusions will not change even if the instrument error is overestimated.

We expect that a slow-down in the ozone trend will occur in a predictable spatial pattern in latitude and altitude. In

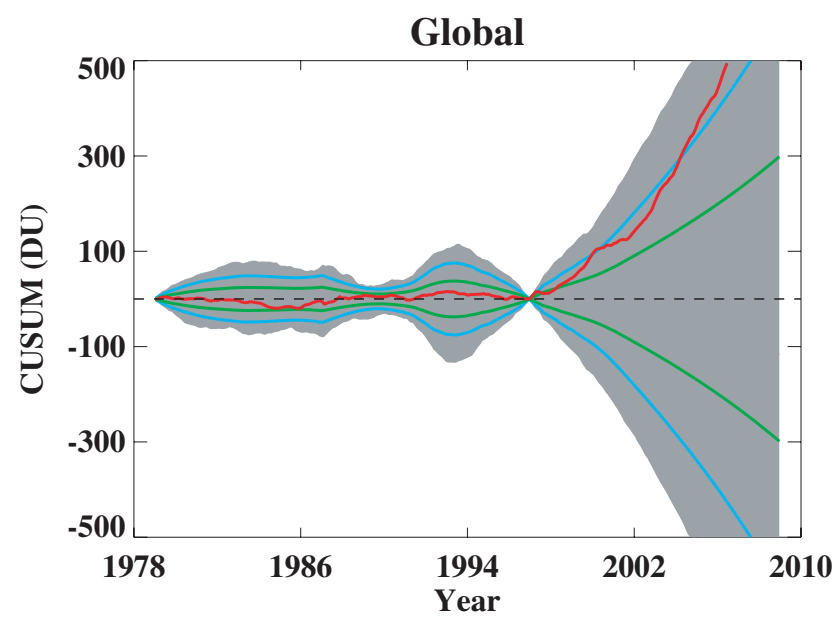

Fig. 10. Same as Fig. 9 with the uncertainty due to possible drift in the instrument record included.
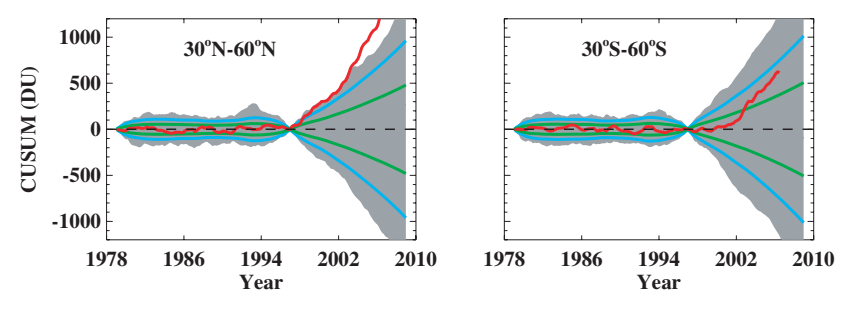

Fig. 11. Cumulative sum of residuals for the northern mid-latitudes $\left(30^{\circ}-60^{\circ} \mathrm{N}\right)$ in left panel, and southern mid-latitudes $\left(30^{\circ}-60^{\circ} \mathrm{S}\right)$ in right panel. Definition of lines is the same as Fig. 10.

altitude, this initial phase of recovery is expected, and has been reported, in the upper stratosphere (Newchurch et al., 2003). For total ozone, we expect to see a trend slow-down attributable to chlorine/bromine in both hemispheres as the concentrations of the chlorine and bromine compounds peak and begin to decline in both hemispheres. Simulations using the Goddard 3-D chemical transport model (Douglass et al., 1997; Douglass et al., 2003) indicate that trend slowdown and eventual recovery occurred in both hemispheres at nearly, but not exactly the same rate (Stolarski, et al., 2006). The hemispheric asymmetry observed in the CUSUM rate of change is likely due to dynamical/transport changes that are not accounted for in our statistical model. Recent data (Yang et al., 2006; Dhomse et al., 2006) and modeling (Hadjinicolaou et al., 2005) studies indicate that the increase in total ozone since the mid-1990s is dominated by yearto-year variations in dynamics rather than the leveling off of chlorine/bromine in the stratosphere. The southern midlatitudes potentially have a smaller dynamical signal and the CUSUM builds more slowly and then, in about 2002, begins a rapid climb that may be in response to the changing chlorine/bromine signal. 
The data shown in Fig. 11 suggest that trend slow-down attributable to chlorine and bromine is occurring, but the observations do not yet indicate the statistically significant slow-down in both hemispheres as will almost certainly be seen in the next few years.

\section{Summary and conclusions}

We have described our method for constructing a merged data set of total column ozone amount. This data set has been available in previous versions on our website at http://code916.gsfc.nasa.gov/Data_services/merged for several years. It has been used in a significant number of papers and has been compared to global data sets put together by others in Fioletov et al. (2002). The newest version extends through June 2006 and uses the Version 8 TOMS and SBUV data.

In this study we present our first uncertainty analysis of the MOD data set. We account for individual instrument drift uncertainties, and the uncertainty associated with properly combining and adjusting the individual records to a common calibration. We then investigate the impact of the MOD data set uncertainty in trend analyses. We emphasize that individual and merged data sets have uncertainties associated with them. Inclusion of estimates of instrument uncertainty is crucial to determination of the significance of trends or recovery.

We apply our data set with uncertainty estimates to the question of detecting a slow-down of the observed trend in total ozone, using the cumulative sum (CUSUM) method previously employed by Yang et al. (2006). To estimate the statistical uncertainty, we use a Monte-Carlo approach to model the potential impact of statistical errors in the derived trend directly. We include both the autoregressive and white-noise characteristics of the data in many new realizations, and calculate the CUSUM from a trend fit over the period through 1996, then extrapolated through June 2006. The range of resulting CUSUM values gives a direct measure of significance requirements. Our statistical errors using this direct approach compare well with those derived by Yang et al. (2006) using a theoretical approach. However, when inherent instrument errors are also taken into account, the significance of the CUSUM results change substantially. This is particularly true for the extra-polar average, where the statistical error is small.

The slow-down in trend for the extra-polar average $\left(60^{\circ} \mathrm{S}\right.$ to $60^{\circ} \mathrm{N}$ ) has varied about the $2 \sigma$ significance level since $\sim 2000$, and in recent months has extended modestly above this criterion. When the data are separated into northern and southern mid-latitude regions, both time series indicate a slow-down in the negative trend. The northern mid-latitude result is significant at the $2 \sigma$ level, but currently the southern mid-latitude result is only significant at the $1.6 \sigma$ level. Our statistical model fit does not include terms for dynamical variability and transport, so these signals will remain in the residual and be included in the CUSUM. The hemispheric asymmetry of the trend slow-down is likely due to an added contribution of dynamical variability in the Northern Hemisphere. This conclusion is supported by recent studies indicating total column and lower stratospheric ozone variability in the Northern Hemisphere is responding to dynamical signals (Yang et al., 2006; Dhomse et al., 2006; Hadjinicolaou et al., 2005). Therefore we conclude that while suggestive, demonstrating a statistically significant response of total column ozone to the leveling off of chlorine and bromine compounds in the atmosphere will require more time and a longer data record.

Acknowledgements. The authors would like to thank the TOMS and SBUV instrument team members (NASA, NOAA and SSAI) for their work in preparing the TOMS and SBUV long-term data sets and their invaluable input on best use of the data. We also thank the three anonymous reviews for their comments and suggestions.

Edited by: M. Dameris

\section{References}

Ahn, C., Bhartia, P. K., Wellemeyer, C. G., Taylor, S. L., and Labow, G. L.: "Validating V8 SBUV ozone profile data with external data sources (microwave, LIDAR and sonde)", Proceedings of the XX Quadrennial Ozone Symposium, Kos, 1-8 June, Greece, 2004.

Anderson, J., Russell, J. M., Solomon, S., and Deaver, L. E.: "Halogen occultation experiment confirmation of stratospheric chlorine decreases in accordance with the Montreal Protocol", J. Geophys. Res., 105, 4483-4490, 2000.

Bhartia, P. K., McPeters, R. D., Mateer, C. L., Flynn, L. E., and Wellemeyer, C.: "Algorithm for the estimation of vertical ozone profiles from the backscattered ultraviolet technique", J. Geophys. Res., 101, 18 793-18 806, 1996.

Bhartia, P. K., McPeters, R. D., Stolarski, R. S., Flynn L. E., and Wellemeyer, C. G.: "A quarter century of ozone observations by SBUV and TOMS", Proceedings of the XX Quadrennial Ozone Symposium, Kos, 1-8 June, Greece, 2004.

Deland, M. T., Huang, L.-K., Taylor, S. L., McKay, C. A., Cebula, R. P., Bhartia, P. K., and McPeters, R. D.: "Long-term SBUV and SBUV/2 instrument calibration for Version 8 data", Proceedings of the XX Quadrennial Ozone Symposium, Kos, 1-8 June, Greece, 2004.

Dhomse, S., Weber, M., Wohltmann, I., Rex, M., and Burrows, J. P.: "On the possible causes of recent increases in northern hemisphere total ozone from a statistical analysis of satellite data from 1979 to 2003", Atmos. Chem. Phys., 6, 1165-1180, 2006, http://www.atmos-chem-phys.net/6/1165/2006/.

Douglass, A. R., Rood, R. B., Kawa, S. R., and Allen, D. J.: “A three-dimensional simulation of the evolution of the middle latitude winter ozone in the middle stratosphere", J. Geophys. Res., 102, 19217-19232, 1997.

Douglass, A. R., Schoeberl, M. R., Rood R. B., and Pawson, S.: "Evaluation of transport in the lower tropical stratosphere in a 
global chemistry and transport model”, J. Geophys. Res., 108, 4259, doi:10.1029/2002JD002696, 2003.

Fioletov, V. E., Bodeker, G. E., Miller, A. J., McPeters, R. D., and Stolarski, R.: "Global and zonal total ozone variations estimated from ground-based and satellite measurements: 1964-2000”, J. Geophys. Res., 107, 4647, doi:10.1029/2001JD001350, 2002.

Frederick, J. E., Cebula, R. P., and Heath, D. F.: "Instrument characterization for the detection of long-term changes in stratospheric ozone: An analysis of the SBUV/2 radiometer", J. Atmos. Oceanic Technol., 3, 472-480, 1986.

Hadjinicolaou, P., Pyle. J. A., and Harris, N. R. P.: “The recent turnaround in stratospheric ozone over northern middle latitudes: A dynamical modeling perspective", Geophys. Res. Lett., 32, L12821, doi:10.1029/2005GL022476, 2005.

Heath, D. F., Krueger, A. J., Roeder, H. R., and Henderson, B. D.: "The solar backscatter ultraviolet and total ozone mapping spectrometer (SBUV/TOMS) for Nimbus G”, Opt. Eng., 14, 323$331,1975$.

Herman J. R., Hudson, R., McPeters, R., Stolarski, R., Ahmad, Z., Gu, X. Y., Taylor S., and Wellemeyer, C.: "A new self-calibration method applied to TOMS and SBUV backscattered ultraviolet data to determine long-term global ozone change", J. Geophys. Res., 96, 7531-7545, 1991.

Hilsenrath, E., Cebula, R. P., Deland, M. T., Laamann, K., Taylor, S., Wellemeyer, C., and Bhartia, P. K.: "Calibration of the NOAA-11 Solar Backscatter Ultraviolet (SBUV/2) Ozone Data Set from 1989 to 1993 using In-Flight Calibration Data and SSBUV", J. Geophys. Res., 100, 1351-1366, 1995.

Labow, G. J., Meters, R. D., and Bhartia, P. K.: "A comparison of TOMS, SBUV \& SBUV/2 total column ozone data with data from groundstations", Proceedings of the XX Quadrennial Ozone Symposium, Kos, 1-8 June, Greece, 2004.

McPeters, R. D., Bhartia, P. K., Krueger, A. J., et al., "Nimbus-7 Total Ozone Mapping Spectrometer (TOMS) data product user's guide", NASA Ref. Pub. No. 1384, 1996.

McPeters, R. D., Bhartia, P. K., Krueger, A. J., et al., "Earth Probe Total Ozone Mapping Spectrometer (TOMS) data product user's guide", NASA/TP-1998-206895, 1998.

Montzka, S. A., Butler, J. H., Elkins, J. W., Thompson, T. M., Clarke, A. D., and Lock, L. T.: "Present and future trends in the atmospheric burden of ozone-depleting substances", Nature, 398, 690-694, 1999.
Montzka, S. A., Butler, J. H., Hall, B. D., Mondeel D. J., and Elkins, J. W.: "A decline in tropospheric organic bromine", Geophys. Res. Lett., 30(15), 1836, doi:10.1029/2003GL017745, 2003.

Newchurch, M. J., Yang, E.-S., Cunnold, D. M., Reinsel, G. C., Zwodny, J. M., and Russell III, J. M.: "Evidence for slowdown in stratospheric ozone loss: First stage of ozone recovery", J. Geophys. Res., 108, 4507, doi:10.1029/2003JD003471, 2003.

Reinsel G. C.: "Trend analysis of upper stratospheric Umkehr ozone data for evidence of turnaround”, Geophys. Res. Lett., 29, 1451, doi:10.1029/2002GL014716, 2002.

Rinsland, C. P., Mathieu, E., Zander, R., Jones, N. B., Chipperfield, M. P., Goldman, A., Anderson, J., Russell, J. M., Demoulin, P., Notholt, J., Toon, G. C., Blavier, J. F., Sen, B., Sussmann, R., Wood, S. W., Meier, A., Griffith, D. W. T., Chiou, L. S., Murcray, F. J., Stephen, T. M., Hase, F., Mikuteit, S., Schulz, A., and Blumenstock, T.: "Long-term trends of inorganic chlorine from ground-based infrared solar spectra: Past increases and evidence for stabilization”, J. Geophys. Res., 108, 4252, doi:10.1029/2002JD003001, 2003.

Staehelin, J., Harris, N. R. P., Appenzeller, C., and Eberhard, J.: "Ozone trends: A review", Rev. Geophys., 39, 231-290, 2001.

Stolarski, R., Bojkov, R., Bishop, L., Zerefos, C., Staehelin, J., and Zawodny, J.: "Measured trends in stratospheric ozone", Science, 256, 342-349, 1992.

Stolarski, R. S., Douglass, A. R., Steenrod, S., and Pawson, S.: "Trends in stratospheric ozone: Lessons learned from a 3D chemical transport model", J. Atmos. Sci., 63, 1028-1041, 2006.

Taylor, S. L., Cebula, R. P., Deland, M. T., Huang, L. K., Stolarski, R. S., and McPeters, R. D.: "Improved calibration of NOAA-9 and NOAA-11 SBUV/2 total ozone data using in-flight validation methods", Int. J. Remote Sensing, 24, 315-328, 2003.

WMO (World Meteorological Organization): "Scientific Assessment of Ozone Depletion: 1998”, Global Ozone Research and Monitoring Project-Report No. 44, Geneva, 1999.

WMO (World Meteorological Organization): "Scientific Assessment of Ozone Depletion: 2002", Global Ozone Research and Monitoring Project-Report No. 47 Geneva, 2003.

Yang, E. -S., Cunnold, D. M., Salawitch, R. J., McCormick, M. P., Russell III, J. J., Zawodny, M., Oltmans, S., and Newchurch, M. J.: "Attribution of recovery in lower-stratospheric ozone", Journal of Geophysical Research, in press, pre-print available at http://science.nasa.gov/headlines/y2006/images/ozone/ preprint.pdf, 2006. 